\title{
IkOnlk PERAN MUSIK SEBAGAI MEDIA INTERVENSI DALAM LINGKUP PRAKTIK KLINIS
}

Volume 2, Nomor 2 Juli 2020, (81-86)

\section{Yanuarius Jefri Kriswanto}

Penciptaan Seni Musik

Pascasarjana Institut Seni Indonesia

e-mail : jefri_kriswanto@yahoo.com

\begin{abstract}
ABSTRAK
Banyak ahli dan pakar psikologi meneliti peran musik terhadap proses penyembuhan pada praktik klinis untuk berbagai macam penyakit. Dewasa ini musik dan elemen yang terkandung di dalamnya sering digunakan sebagai media intervensi selama proses penyembuhan medis berlangsung. Tujuan penelitian ini adalah untuk mengetahui sejauh mana musik dapat berperan sebagai media intervensi dalam praktik klinis. Metodologi yang digunakan dalam penelitian ini adalah studi pustaka dengan memanfaatkan jurnal online, buku serta disertasi. Hasilnya adalah musik sebagai media intervensi ternyata sangat membantu dalam pasien mengatasi rasa takut, cemas, dan nyeri baik sebelum, selama, dan setelah proses perawatan medis berlangsung. Lebih dari itu, Intervensi musik pada pasien terbukti dapat membangun rasa percaya diri serta memunculkan energi positif dari hasil pengalaman menyenangkan yang telah dialami sebelumnya. Hal ini tentunya sangat baik untuk memajukan kualitas hidup dan kesejahteraan psikologis pasien.
\end{abstract}

Kata kunci: media intervensi, terapi musik aktif, terapi musik reseptif

\begin{abstract}
Many experts and psychologists examine how big music is taking a role in the healing process in clinical practice for various diseases. Nowdays music and the elements contained in it are often used as a medium of intervention during the medical healing process. The purpose of this study is to determine the extent to which music can act as a medium of intervention in clinical practices. The methodology used in this research is literature approach by utilizing online journals, books, and dissertations. The result is music as an intervention media is very helpful in patients in order to overcome fear, anxiety, and pain both before, during, and after the medical treatment process. More than that, music intervention in patients is proven to build self-confidence and generate positive energy which are coming from their pleasant experiences they feel before. This is certainly very good for advancing the quality of life and psychological well-beeing of them..
\end{abstract}

Keywords: intervention media, active music therapy, receptive music therapy

\section{PENDAHULUAN}

Musik sebagai salah satu cabang kesenian merupakan kebutuhan yang universal. Keberadaannya tidak terpisahkan dalam berbagai setting kehidupan manusia dengan berbagai fungsinya seperti : (1) memberikan kenikmatan estetis; (2) memberikan efek relaksasi atau hiburan; (3) sebagai media ekspresi diri (self-expression); (4) representasi simbolis; (5) respon fisik; (6) media terapeutik; ( penyembuhan); (7) sebagai sarana pemersatu masyarakat yang sedang mengalami krisis; (8) meningkatkan konformitas terhadap norma-norma sosial; (9) memvalidasi institusiinstitusi sosial dan ritual keagamaan; (10) memelihara kontinyuitas dan stabilitas budaya; (11) sebagai media pendidikan serta pembelajaran (Budhisantoso, 1994; Merriam, 1968; dan Merrit, 2003).
Keberadaan musik sebagai media terapi pada masyarakat kita dewasa ini merupakan salah satu fenomena yang menarik untuk dikaji. Meski hal ini belum banyak mendapat perhatian dari kalangan akademisi, namun secara praktis ternyata telah dikembangkan oleh lembaga pendidikan serta klinik kesehatan tertentu.

Terapi musik adalah tipe terapi non-verbal yang berbeda dengan terapi konvensional lainnya. Karena terapi musik memberikan alternatif bagi terapi tradisional dan melengkapi klien dengan beberapa keunggulan seperti : (1) memberi peluang berpikir serta merasakan secara langsung; (2) memberi peluang "mengisi" perasaan utuk beberapa periode sehingga bisa dieksplorasi, diuji, dan diolah lewat kerja sama dengan terapis; (3) mengkondisikan ekpresi pikiran dan perasaan klien secara non-verbal; (4) diperoleh perumpamaan dan asosiasi yang tidak dapat diakses melalui pemahaman verbal; (5) diperoleh keuntungan 
fisiologis secara langsung melalui kebebasan bereksplorasi dan mencoba berbagai solusi terhadap pikiran dan perasaan melalui cara-cara yang kreatif (Djohan, 2003: 190-191).

Dalam praktik klinis, musik digunakan untuk meringankan rasa nyeri atau sakit dalam hubungannya dengan anestesi atau obat pereda nyeri, meningkatkan mood pasien dan mengurangi depresi, mempromosikan gerakan untuk rehabilitasi fisik, melawan ketakutan, dan mengurangi ketegangan otot. Meskipun intervensi farmakologi sudah diimplementasikan, seperti pemberian obat-obatan, hal tersebut masih memberi dampak efek samping bagi pasien. Sehingga dapat dikatakan peran musik dalam hal ini lebih difokuskan sebagai terapi pelengkap atau media intervensi dalam proses penyembuhan yang sedang berlangsung. Kehadiran musik sebagai media intervensi non-pharmacological dapat memberikan rasa tenang dan nyaman pada pasien, sehingga proses penyembuhan atau healing yang berjalan bisa efektif dan lebih efisien.

\section{METODE PENELITIAN}

Metode penelitian yang dipakai dalam penulisan ini adalah studi pustaka dengan sumber berupa artikel, buku, jurnal online dengan tujuan untuk menelaah sejauh mana peran musik sebagai media intervensi dalam berbagai praktik klinis. Penggunaan musik baik sebagai stimulus maupun terapi dapat memberikan solusi alternative untuk berbagai kondisi penyakit yang sebagian besar belum dapat disembuhkan secara klinis.

\section{HASIL DAN PEMBAHASAN}

beritmik dalam praktik medis memiliki sejarah yang panjang dan sering digunakan untuk meningkatkan dan menjaga kondisi fisik dan psikologi seseorang. Sejarah mencatat, penggunaan musik dalam praktik penyembuhan bermula sejak peradaban Romawi dan Yunani kuno khususnya dalam terapi spa. Pada praktik ini, para musisi disewa untuk memberikan efek healing bagi para pengguna spa kala itu melalui karyanya. (Bernatzky, 2011: 11).

Menurut World Federation of Music Therapy (WFMT) padatahun 2011,

"Terapi musik adalah penggunaan musik secara professional serta unsur-unsurnya sebagai intervensi dalam lingkungan medis, pendidikan, dan keseharian individu, kelompok, keluarga, ataukomunitas yang berupaya mengoptimalkan kualitashidup mereka dan juga meningkatkan kondisi fisik, sosial, komunikasi, emosi, kesehatan, serta kesejahteraan intelektual dan spiritual. Penelitian, praktik, pendidikan, dan pelatihan klinis dalam terapi musik didasarkan pada standar professional sesuai kontekssosial, budaya, danpolitiksetempat".

Menurut G. Bernatzky dalam artikelnya yang berjudul Neuroscience and Biobehavioral reviews, 2011 secara umum praktik terapi musik dibagi ke dalam dua kategori; yakni terapi musik receptive dan terapi musik aktif. Terapi musik receptive sering digunakan sebagai terapi pelengkap dari bentuk praktik terapi lainnya, dengan menggabungkan musik pilihan pasien melalui konsultasi dengan terapisnya terlebih dahulu. Intervensi musik sering dipakai untuk membangkitkan emosi tertentu, yang memudahkan pasien untuk mengingat, merasakan, dan menggali ingatan atau pengalaman yang pernah dirasakannya dan memahami peranan pengalaman tersebut dalam konteks aktual.

Sedangkan terapi musik aktif secara total berbeda dengan terapi musik receptif. Terapi ini membutuhkan partisipasi pasien untuk turut serta bersama terapis terlatih menciptakan musik dan juga gerakan tubuh. Terapis dan pasien akan bernyanyi dan atau memainkan instrumen musik tertentu secara bersama-sama. Terapis kemudian akan mendorong pasien untuk melakukan improvisasi dalam gerakan tubuh. Sehingga dapat dikatakan perbedaan mencolok dari dua jenis terapi musik di atas adalah; terapi musik receptive mendorong pasien mengingat kembali pengalaman beserta emosi yang pernah dialami, ketika terapi musik aktif lebih mendorong pasien untuk menciptakan pengalaman actual ketika berimprovisasi. Kombinasi dari kedua jenis terapi ini adalah latihan "forward-looking" yang mutlak.

Niscaya kedua jenis terapi ini memiliki kelebihan dan kekurangan masing-masing. Di satu sisi, terapis harus mendapatkan pelatihan yang komprehensif dan mendalam untuk menciptakan konsep yang jelas terhadap objek terapi. Di lain pihak, terapis harus mempunyai pemahaman yang baik akan elemen musik serta efek potensial yang bisa ditimbulkan untuk bisa mencapai tujuan dari terapinya pada pasien.

Pada terapi musik emosi yang timbul tadi, merupakan topik dan dasar bagi terapi untuk berbincang dengan pasiennya, meningkatkan rasa percaya diri pasien, dan lain-lain. Pada terapi musik, baik terapis dan pasien bernyanyi dan atau memainkan instrument musik bersama-sama, selanjutnya pasien akan didorong oleh terapis untuk melakukan improvisasi melalaui gerakan tubuh sesuai dengan perasaanya pada saat itu.

Telah dibuktikan oleh para peneliti bahwa musik berpengaruh terhadap detak jantung (HR) dan variabelnya (HRV) (Trappe, 2009). Aksen dan ritme yang ada pada musik akan beresonansi secara baik dengan kondisi fisik dan psikologi individu. Meski demikian reaksi terhadap musik yang didengar sangat subjektif, namun penelitian yang 
dilakukan mengukuhkan bahwa variabel-variabel pada respirasi kardio yang berangsung di dalam tubuh sangat dipengaruhi oleh kondisi lingkungan tepat individu berada (BradtdanDileo, 2009).

Rasa cemasatautakutadalahhal yang seringdijumpaipadakasuspengobatan medis. Hal ini melanda tidak hanya anak-anak tetapi juga pada sebagian besar orang dewasa. Kondisi ini membuat intervensi non-farmakologi dalam upaya menangani rasa cemas pasien, seperti memperdengarkan alunan musik, dibutuhkan dan dewasa ini sering diaplikasikan pada banyak klinik.

Banyak bukti tidak terbantahkan tentang penggunaan intervensi musik yang sangat efektif di berbagai bidang penyembuhan medis. Bukti dari Cochrane dalam reviewnya yang sistematis telah mengindikasikan bahwa intervensi musik cukup besar pengaruhnya pada rasa takut/cemas yang dirasakan para pasien kanker(Bradt, 2016), dan pasien pengidap penyakit jantung coroner (Bradt, 2013a). Selain itu mendengarkan musik juga sangat membantu mengantisipasi rasa takut/cemas yang muncul akibat stress sebelum mengikuti ujian (Afzal, 2012), dan sesaat sebelum seseorang menjalani proses pembedahan.

Penggunaan intervensi musik dalam dunia medis dapa tditempatkan di seluruh rangkaian proses perawatan, bermula dari mendengarkan musik sesuai selera pasien, ke obat musik (music medicine), yakni mendengarkan musik tertentu yang ditawarkan oleh tenaga medis dalam upaya penyembuhan, sampai pada sesi terapi musik, yakni intervensi musik individual yang diprakarsai oleh terapis profesional (Bradt, 2015).

Intervensi terapi musik tidak berarti sekedar mendengarkan msuik tertentu. Sesi terapi musik membutuhkan pengamatan terapis musik untuk bisa menciptakan metode penyembuhan yang bisa menjawab kebutuhan pasien. Proses ini dapat berupa metode reseptif seperti relaksasi dibantu musik, atau mendengarkan musik secara langsung yang dimainkan oleh si terapis. Dapat juga berupa metode re-kreatif, yakni memainkan musik yang dikomposisi sebelumnya oleh pasien dan terapis, dan berupa metode improvisasi dimana pasien dan terapis mengimprovisasi musik secara bersamasama melaui instrumental, vokaldan juga gerak tubuh.

Ada sejumlah faktor yang dapat mempengaruhi respon seseorang terhadap musik. Faktor ini mencakup usia, jenis kelamin, fungsi kognitif, level kecemasan, ketertarikan dan kedekatan dengan jenis musik tertentu, dan kondisi budaya seseorang (Standley, 2000; Pelletier, 2004).

Oleh sebab itu, bagi mereka dengan tingkat kecemasan yang sangat tinggi, juga bagi para pasien berkebutuhan khusus, para dokter gigi direkomendasikan untuk menggunakan terapismusik yang profesional. Di bawah ini adalah beberapa panduan klinis bagi para dokter gigi dalam menggunakan intervensi musik dalam praktik mereka.

\section{i. Patient-Preferred Music}

Sebelum menjadwalkan kontrol gigi, dokter atau staf nya sebaiknya menganjurkan pasien untuk membawa serta musik atau lagu favoritnya pada sesi kontrol gigi yang akan datang. Tidak peduli apapun genre musik pasien, pemilihan musik tertentu sesuai seleranya akan membantunya meningkatkan mood juga perhatian dan onsentrasinya dan membuat mereka tetap tenang dalam kondisi yang tidak nyaman sekalipun.

\section{ii. Relaxing Music}

Jika pasien lebih suka mendengarkan musik relaksasi, panduan ini sangat berguna untuk memilih musik relakasi tertentu. Kualitas musik relaksasi sangat identik dengan: struktur, melodi, dan harmoni yang simpel, repetisi melodi dan harmoni, dan instrumen yang melibatkan bunyi riak air, angin, dan piano yang lembut.

\section{iii. Volume Control}

Pasien harus diberikan akses penuh untuk mengontrol volume musik untu mencegah rasa tidak nyaman serta meningkatkan kontrol perasaan.

\section{iv. Use of Headphones or free field}

Pasien harus diberikan kebebasan untuk mendengarkan musik dengan atau tanpa mengguakan headphones.

\section{$v$. Timing of the music intervention}

Sangat penting bagi pasien untuk mendengarkan musik sebelum berlansungnya proses kontrol gigi terutama sebelum pencabutan gigi,untuk membantu mereka mengurangi rasa cemas yang mereka alami.

\section{vi. Active Engangement}

Sangat direkomendasikan bagi para dokter untuk mengintruksikan pasiennya agar benarbenar fokus pada musik, dan bukan sekedar mendengarkan musik.

\section{KESIMPULAN}

Hasil dari penelitian ini menunjukan bahwa musik memegang peranan penting sebagai media intervensi atau pelengkap dari bentuk terapi lain dalam konteks meringankan rasa nyeri atau perasaan cemas berlebihan. Dalam kasus-kasus tertentu musik bisa jadi elemen pelengkap dan bahkan bisa menggantikan peran obat-obatan farmasi sebelum, selama, dan setelah proses penyembuhan.

Pada dasarnya musik sebagai media intervensi dan terapi memiliki tiga karakteristik dasar. Pertama, musik memilik penngaruh pada sistem saraf pusat khususnya sitem limbic dan efeknya digeneralisasikan secara luas meliputi tubuh, pikiran, emosi, dan mental. Kedua, musik 
dapat digunakan untuk mengurangi bahkan menggantikan peran obat, dimana hal ini bisa menekan harga pengobatan. Dan ketiga, efek samping dari terapi musik sangat minim bahkan bisa diabaikan sehingga terapi musik dapat dimasukan sebagai intervensi pelengkap dalam proses pengobatan major.

Terapi musik mungkin akan efektif bila dikombinasikan dengan mode perawatan lain. Dalam banyak kasus, intervensi musik tidak dapat sepenuhnya menghilangkan rasa sakit dan stres tetapi lebih ditujukan pada pemfasilitasian dan pengelolaan sistem tubuh-otak yang relevan, yang bisa meningkatkan fungsionalitas setiap organ tubuh. Terapi musik bisa menjadi sarana yang sederhana dan efektif untuk meningkatkan keuntungan psikosomatis ini.

Yang pasti adalah terapi musik tidak memilik efek samping yang berbahaya. Dengan begitu treatmen ini dapat diaplikasikan pada pengobatan medis yang beresiko, sebagai media intervensi ataupun media pelengkap yang sangat membantu pasien dalam pemahaman nya tentang hubungan antara pikiran, otak, dan tubuh. Sampai di tahap ini, pasien diharapkan mampu mengatasi rasa tidak nyaman yang muncul akibat pengobatan medis melalui energi positif dari dalam dirinya yang diperoleh dengan adanya intervensi musik selama proses perawatannya.

\section{DAFTAR PUSTAKA}

Afzal, H., Afzal, S., Siddique, S., Naqvi, S.A. 2012. "Measures Used by Medical Students to Reduce Test Anxiety".J Pak Med Assoc 62: 982 - 986.

Albert, R.E. 2002. "The Effect of Guided Imagery and Music on Pain and Anxiety during Laceration Repair". [Disertasi]. US: University Microfilms Int.

Aitken, J.C. 2002. "The Effect of Music Distraction on Pain, Anxiety and Behavior in Paediatric Dental Patients. Pediatric Dentistry 24, 114 118.

Almeida, P.Z. 2003. "The Effect of Music Therapy and Guided Imagery on Postoperative Pain, Anxiety and Medication Use: a Prospective Randomized Study". Gynecologic Oncology 88, 198 - 199.

Bernatzky, G. 2011. "Emotional Foundations of Music as a Non-Pharmacological Pain Management Tool in Modern Medicine". INVENSI (Neuroscience and Biobehavioral Reviews), NBR 1480,1 - 11.

Bernatzky, G. 2012. "Music as Non-Pharmacological Pain Management in Clinics". Chapter 19, 257 $-275$.

Bernatzky, G. 2012. "Neurochemical Consequences of Daily Music on Young Socially-Housed and
Isolated Chicks". Society for Neurosience Abstract 24, 1199.

Bernatzky, G. 2012. "Effects of Music on Neurochemical Parameters in the Avian Brain". Society for Neurosience Abstract 23, 235.

Bradt, J. 2011. "Music Interventions for Dental Anxiety". INVENSI (Oral Disseases), 300 - 306.

Bradt, J., Dileo, C. 2009. "Music for Stress and Anxiety Reduction in Coronary Heart Disease Patients".Cochrane Database of Systematic Reviews 15, CD006577.

Bradt, J. 2010. "Music Therapy for End-of-Life Care".Cochrane Database of Systematic Reviews, CD007169.

Bradt, J. 2010. "Music Therapy for Acquired Brain Injury".Cochrane Database of Systematic Reviews, CD006787.

Bradt, J.,Dileo, C., Magill, L., Teague, A. 2016. “Music Interventions for Improving Psychological and Physical Outcomes in Cancer Patients".Cochrane Database of Systematic Reviews 8, CD006911.

Bradt, J.,Dileo, C., Magill, L., Potvin, N. 2013a. “Music for Stress and Anxiety Reduction in Coronary Heart Disease Patients".Cochrane Database of Systematic Reviews 12, CD006577.

Bradt, J., Potvin, N., Kesslick, A.dll.2015. “The Impact of Music Therapy Versus Music Medicine on Psychological Outcomes and Pain in cancer Patients: a Mixed Method Study".Support Care Cancer 23, 1261 - 1271.

Brown, S. 2004. "Passive Music Listening Spontaneously Engages Limbic and Paralimbic Systems".Neuroreport Auditory and Vestibular Systems 15, 2033 - 2037.

Budhisantoso. 2004. "Kesenian dan Kebudayaan". Jurnal Seni Tahun I. 1 - 12.

Capeda, M.S. 2006. "Music for Pain Relief". Cochrane Database Systems 19, CD004843.

Chan, M.F. 2009. "Effects of Music on Depression Levels and Physiological Responses in Community-Based Older Adults".International Journal of Mental Health and Nursing 18, 285 $-294$.

Djohan.2003. Psikologi Musik. Yogyakarta : Buku Baik.

Engwall, M. 2009. "Music as a Nursing Intervention for Postoperative Pain: a Systematic Rewiews". Journal of Perianesthesia Nursing 24, 370 383.

Merriam, A. P.1968. The Anthropology of Music. US : North Western University Press.

Merrit, S.2003. Simponi Otak. Bandung : Mizan Media Utama.

Pelletier,C.L. 2004. "The Effect of Musicon Decreasing Arousal Due to Stress : a Metanalysis".Journal of Music Therapy41, 192 - 214. 
Pratt,R.R.,Spintge, R.1996. Music Medicine Vol II.Saint Luis: MMB Music.

Spintge,R.,Droh, R.1992a.Music Medicine Vol I. Saint Luis: MMB Music.

Standley, J. 2000. "Effectiveness of Music Therapy Procedures: Documentation of Research and
Clinical Practice".American Music Therapy Association: Silver Spring MD,1 - 64.

Trappe,H. J. 2009. "Music and Health-What Kind of Music is Helpful for Whom ? What Music Not?".Deutsche Medizinische Wochenschrift134, 2601- 2606. 
Yanuarius Jefri Kriswanto / IKONIK : Jurnal Seni dan Desain, Vol. 2, No.2, Juli 2020, 81-86

(Halaman ini sengaja dikosongkan) 